\title{
Endothelin and sex hormones modulate the fibronectin synthesis by cultured human skin scleroderma fibroblasts
}

\author{
S Soldano, ${ }^{1}$ P Montagna, ${ }^{1}$ B Villaggio, ${ }^{2}$ A Parodi, ${ }^{3}$ G Gianotti, ${ }^{3}$ A Sulli, ${ }^{1}$ B Seriolo, \\ M E Secchi, ${ }^{1}$ M Cutolo ${ }^{1}$
}

\begin{abstract}
${ }^{1}$ Research Laboratories and Clinical Academic Unit of Rheumatology, Department of Internal Medicine, University of Genova, Italy; ${ }^{2}$ Research Laboratories and Clinical Academic Unit of Nephrology. University of Genova, Italy;

${ }^{3}$ Department of Endocrinological and Medical Science, Unit of Dermatology, University of Genova, Italy

Correspondence to: M Cutolo, Research Laboratories and Clinical Academic Unit of Rheumatology, Department of Internal Medicine, University of Genova, Viale Benedetto XV, 6 , 16132 Genova, Italy; mcutolo@ unige.it
\end{abstract}

Accepted 5 October 2008 Published Online First 24 October 2008

\author{
ABSTRACT \\ Objective: To evaluate the influence of endothelin-1 (ET- \\ 1) and sex hormones on cell proliferation and extracellular \\ matrix (ECM) synthesis (ie, fibronectin, laminin) by \\ cultured normal and scleroderma (SSc) human skin \\ fibroblasts (FBs).
}

Methods: Primary cultures of FBs were treated with ET-1 and sex hormones (17 $\beta$-oestradiol or testosterone) for $24 \mathrm{~h}$. Cell growth was analysed by methiltetrazolium salt test, ECM synthesis was evaluated by immunocytochemistry and western blot, both at $24 \mathrm{~h}$.

Results: In normal FBs, ET-1 and 17 $\beta$-oestradiol, as well as their combination, increased cell growth $(p<0.001$, $p<0.001, p<0.01$ vs untreated cells (control), respectively) and fibronectin synthesis ( $p<0.05, p<0.05$, $p<0.01$ vs control, respectively). By contrast, testosterone either alone or in combination with ET-1 did not influence cell proliferation, but decreased fibronectin synthesis $(p<0.05$, testosterone vs control). In SSc FBs, ET-1 and $17 \beta$-oestradiol alone or their combination induced an increased fibronectin synthesis $(p<0.05$, $p<0.05, p<0.01$ vs control, respectively). Unexpectedly, testosterone induced an increase of fibronectin synthesis ( $p<0.05$ vs control)

Conclusions: ET-1 and 17 $\beta$-oestradiol seem to exert a profibrotic effect in normal and SSc culture FBs and might suggest their synergistic effect in the pathogenesis of the fibrotic process in SSc.

Fibrosis is a pathological hallmark of several connective tissue diseases including systemic sclerosis (SSc), in which fibroblasts (FBs) are key effectors of the fibrotic process through an excessive production of extracellular matrix (ECM) components in the skin and internal organs. ${ }^{1}$ Recent evidence suggests that endothelin-1 (ET-1) plays an important role in the pathogenesis of fibrosis by exerting a potent mitogenic effect on FBs and increased ET-1 production in FBs derived from patients with SSc has been found. ${ }^{3}$ Moreover, increased ET-1 plasma levels are observed in patients with SSc. ${ }^{4}$

Clinical and basic data suggest that oestrogens may influence dermal tissue remodelling. ${ }^{5}$ Oestrogens enhance the in vitro production by FBs of basic fibroblast growth factor (BFGF) and transforming growth factor (TGF)- $\beta 1$, inducing their proliferation, migration, production of the $\mathrm{CM}$ and decreasing generation of tissue-degrading matrix metalloproteinases . ${ }^{67}$ In in vivo studies, topical oestrogens increased collagen I and III expression in the dermis. ${ }^{8}$ Interestingly, from the epidemiological evidence, SSc is found significantly more frequently in women than men. ${ }^{9}$

In the present study, we investigated the effects of ET-1 on cultured human SSc and normal skin FBs, and sex hormones on cell proliferation and ECM synthesis (ie, fibronectin, laminin), in order to detect possible synergistic effects on the fibrotic process.

\section{MATERIALS AND METHODS}

\section{Cell cultures and treatments}

Skin biopsies were obtained during diagnostic procedures (Dermatological Clinic, University of Genoa) from six patients with SSc (three women and three men, mean (SD) aged 60 (4) years) and from six healthy subjects (three women and three men, mean (SD) age 55 (10) years), after informed consent and ethical committee approval was obtained. In order to reduce the variability, the patients enrolled into the study showed similar capillaroscopic pattern of microangiopathy ("late" pattern), skin involvement (limited SSc), mean (SD) disease duration (7 (3) years) and ongoing treatments (buflomedil, aspirin, lansoprazole). SSc control FBs obtained from the biopsies were plated into flasks with RPMI-1640 medium supplemented with $10 \%$ fetal bovine serum (FBS). The cells were treated for $24 \mathrm{~h}$ in serum-free medium, with ET-1 having a mitogenic effect $\left(10^{-7} \mathrm{M}\right.$, Axxora, Lörrach, Germany), physiological concentrations of $17 \beta$-oestradiol (E2, $10^{-10} \mathrm{M}$, Sigma-Aldrich, Milan, Italy) or testosterone $\left(\mathrm{T}, 10^{-9} \mathrm{M}\right.$, SigmaAldrich) alone and in combination with ET-1. Untreated cells were used as controls.

In the preliminary stage of the study, we generated a dose-response curve from normal FBs for the agonists analysed in these experiments. For ET-1 we tested a concentration range from $10^{-6} \mathrm{M}$ to $10^{-9} \mathrm{M}$, and at concentration of $10^{-7} \mathrm{M}$, the cells showed an optimal mitogenic response. The same approach was performed for E2 (range from $10^{-7} \mathrm{M}$ to $10^{-12} \mathrm{M}$ ) and $\mathrm{T}$ (range from $10^{-7} \mathrm{M}$ to $\left.10^{-12} \mathrm{M}\right)$ resulting optimal concentrations of $10^{-10} \mathrm{M}$ and $10^{-9} \mathrm{M}$, respectively. These concentrations are usually employed in in vitro studies.

The experiments were performed at $24 \mathrm{~h}$ since the serum-free culture condition was shown to significantly influence the cell survival over longer time.

\section{3-(4,5-Dimethylthiazol-2-yl)-2,5-diphenyltetrazolium bromide (MTT) test}

The MTT test was used to evaluate cell growth. ${ }^{10}$ The FBs were plated into a 96-well tissue culture 


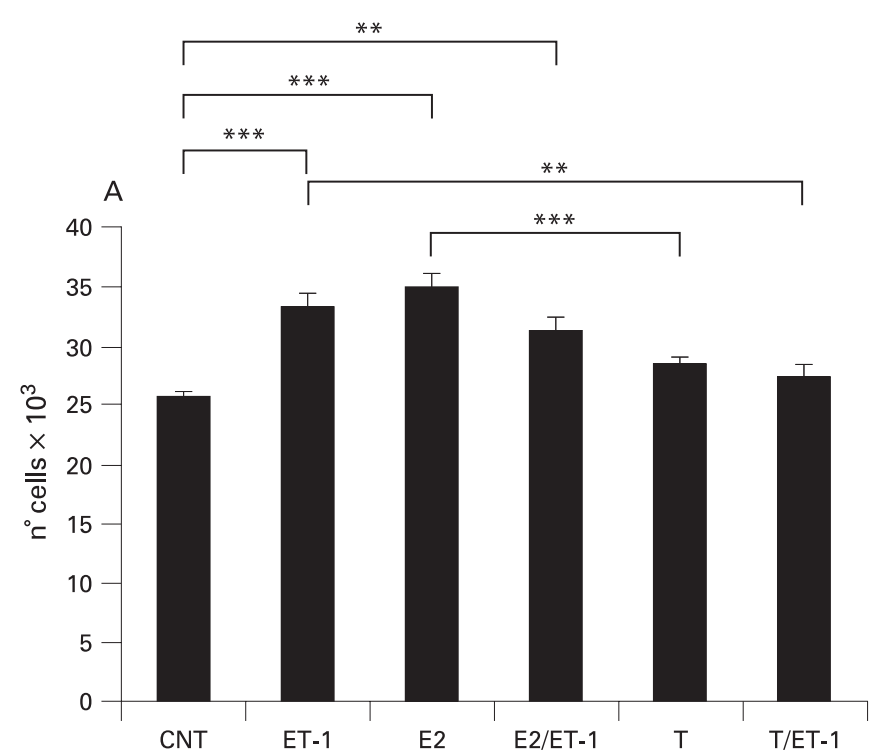

B

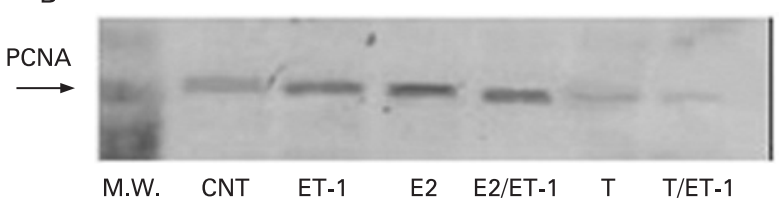

C

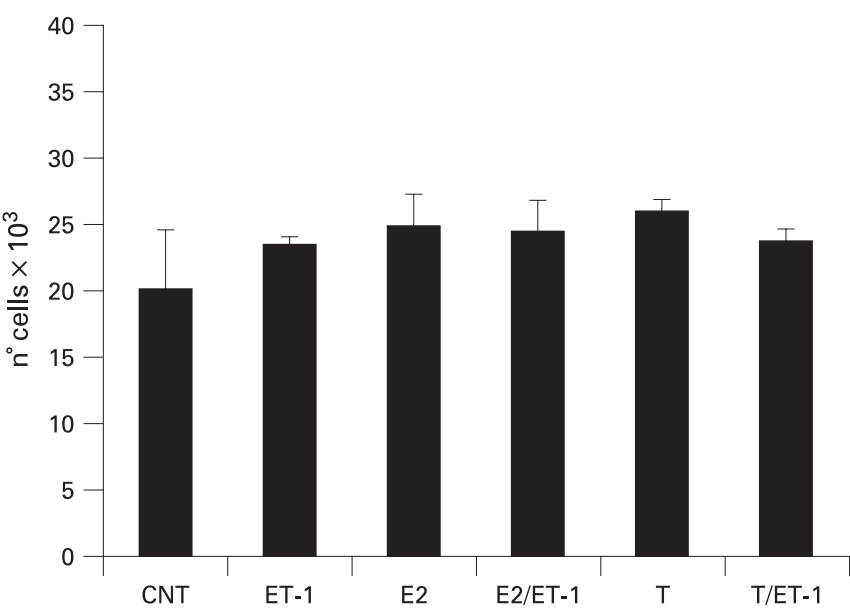

Figure 1 A. Evaluation by 3-(4,5-dDimethylthiazol-2-yl)-2,5diphenyltetrazolium bromide (MTT) test of cell proliferation in human normal fibroblasts ( $\mathrm{Fb})$ untreated (control) and treated for $24 \mathrm{~h}$ with endothelin-1 (ET-1) $\left(10^{-7} \mathrm{M}\right), 17 \beta$-oestradiol (E2) $\left(10^{-10} \mathrm{M}\right)$, E2

$\left(10^{-10} \mathrm{M}\right)$ with ET-1 $\left(10^{-7} \mathrm{M}\right)$, testosterone $(\mathrm{T})\left(10^{-9} \mathrm{M}\right)$ or $\mathrm{T}\left(10^{-9} \mathrm{M}\right)$ with ET-1 $\left(10^{-7} \mathrm{M}\right) .{ }^{* *} \mathrm{p}<0.01 ;{ }^{* * *} \mathrm{p}<0.001$. B. Evaluation by western blot analysis of proliferating cell nuclear antigen (PCNA) expression in human normal $\mathrm{Fb}$ untreated (control) and treated for $24 \mathrm{~h}$ with ET-1 $\left(10^{-7} \mathrm{M}\right), \mathrm{E} 2\left(10^{-10} \mathrm{M}\right), \mathrm{E} 2\left(10^{-10} \mathrm{M}\right)$ with ET-1 $\left(10^{-7} \mathrm{M}\right), \mathrm{T}\left(10^{-9} \mathrm{M}\right)$ or $\mathrm{T}\left(10^{-9} \mathrm{M}\right)$ with ET-1 $\left(10^{-7} \mathrm{M}\right)$. C. Evaluation by MTT test of cell proliferation in human systemic sclerosis fibroblasts (SSc Fb) untreated (control) and treated for $24 \mathrm{~h}$ with ET-1 $\left(10^{-7} \mathrm{M}\right)$, E2 $\left(10^{-10} \mathrm{M}\right), \mathrm{E} 2$ $\left(10^{-10} \mathrm{M}\right)$ with ET-1 $\left(10^{-7} \mathrm{M}\right)$, T $\left(10^{-9} \mathrm{M}\right)$ or $\mathrm{T}\left(10^{-9} \mathrm{M}\right)$ with ET-1 $\left(10^{-7} \mathrm{M}\right)$.

test plate $\left(15 \times 10^{3}\right.$ cells/well $)$ and treated according to the experimental design. At the established time, the cells were incubated at $37^{\circ} \mathrm{C}, 5 \% \mathrm{CO}_{2}$ in presence of MTT labelling reagent (Promega Corporation, San Luis Obispo, California, USA). Absorbance was measured at 492/620 nm. The experiments were performed in triplicate.
Immunocytochemistry

FBs were cultured in Flexi PERM chamber slides $\left(10 \times 10^{3}\right.$ cells/ spot) (Sartorius, Goettingen, Germany) and treated according to the experimental design. At the end of treatment, the cells were incubated with primary antibodies to human fibronectin (Sigma-Aldrich; dilution 1:100), laminin (Sigma-Aldrich; dilution 1:100) and proliferating cell nuclear antigen (PCNA, Santa Cruz Biotechnology, Santa Cruz, California, USA; dilution 1:200). Linked antibodies were detected by biotinylated universal secondary antibody and subsequently horseradish peroxidase-streptavidin complex (Vector Laboratories, Burlingame, California, USA). The slide evaluation was performed on 30 high-power fields for each condition by light microscopy (magnification 40x) and computerised image analysis with the Leica 0500 MC Image Analysis System (Leica, Wetzlar, Germany).

\section{Western blot analysis}

FBs, cultured up to $80 \%$ of confluence, were treated according to the experimental design and lysed. For every condition, $0.02 \mathrm{~g}$ of protein was separated by electrophoresis on a $10 \%$ sodium dodecyl sulfate polyacrylamide gel electrophoresis (SDS-PAGE) gel and transferred into Hybond-C-nitrocellulose membrane (Amersham, Milan, Italy). Membranes were incubated in Dulbecco phosphate buffered saline (DPBS)/5\% powdered milk with primary antibodies: anti-human PCNA (Santa Cruz Biotechnology; dilution 1:200) as marker of cell proliferation; anti-human fibronectin (Sigma-Aldrich; dilution 1:500) and antilaminin (Invitrogen, Carlsbad, California, USA; dilution 1:500) as ECM proteins. Membranes were incubated with secondary horseradish peroxidase-labelled polyclonal IgG antibody (Amersham; dilution 1:5000), protein expression was detected using the enhanced chemiluminescence system (Amersham).

\section{Statistical analysis}

The statistical analysis was carried out using non-parametric $t$ tests. The Wilcoxon test was performed to compare the paired treatments. A probability value of $p<0.05$ was considered statistically significant.

\section{RESULTS}

\section{Effects of ET-1 and sex hormones on cell growth}

ET-1, E2 alone or ET-1 and E2 in combination induced a significant increase of cell proliferation $(p<0.001 ; p<0.001$; $p<0.01$, respectively), whereas $\mathrm{T}$ alone or in combination with ET-1 did not induced differences in normal human skin FBs when compared to the untreated controls (vs control) (fig 1A). The mean values between E2 and $T$ differed significantly $(p<0.001)$ (fig 1A). By contrast, $T$ in combination with ET-1 decreased the cell growth $(p<0.01)$ when compared to ET-1treated FBs (fig 1A). These data were detected by the MTT test.

Cell growth was also evaluated by PCNA expression via western blot analysis. ET-1, E2 alone or ET-1 and E2 in combination were found to increase the PCNA expression vs control. The opposite effect was observed in T-treated cells also in the presence of ET-1 (fig 1B). Interestingly, no significant differences were observed in SSc FBs (fig 1C). These results were also confirmed by immunostaining for PCNA (data not shown).

\section{Effects of ET-1 and sex hormones on ECM synthesis}

Normal fibroblasts

ET-1 induced a significant increase of fibronectin synthesis $(p<0.05$ vs control), whereas no significant difference for 

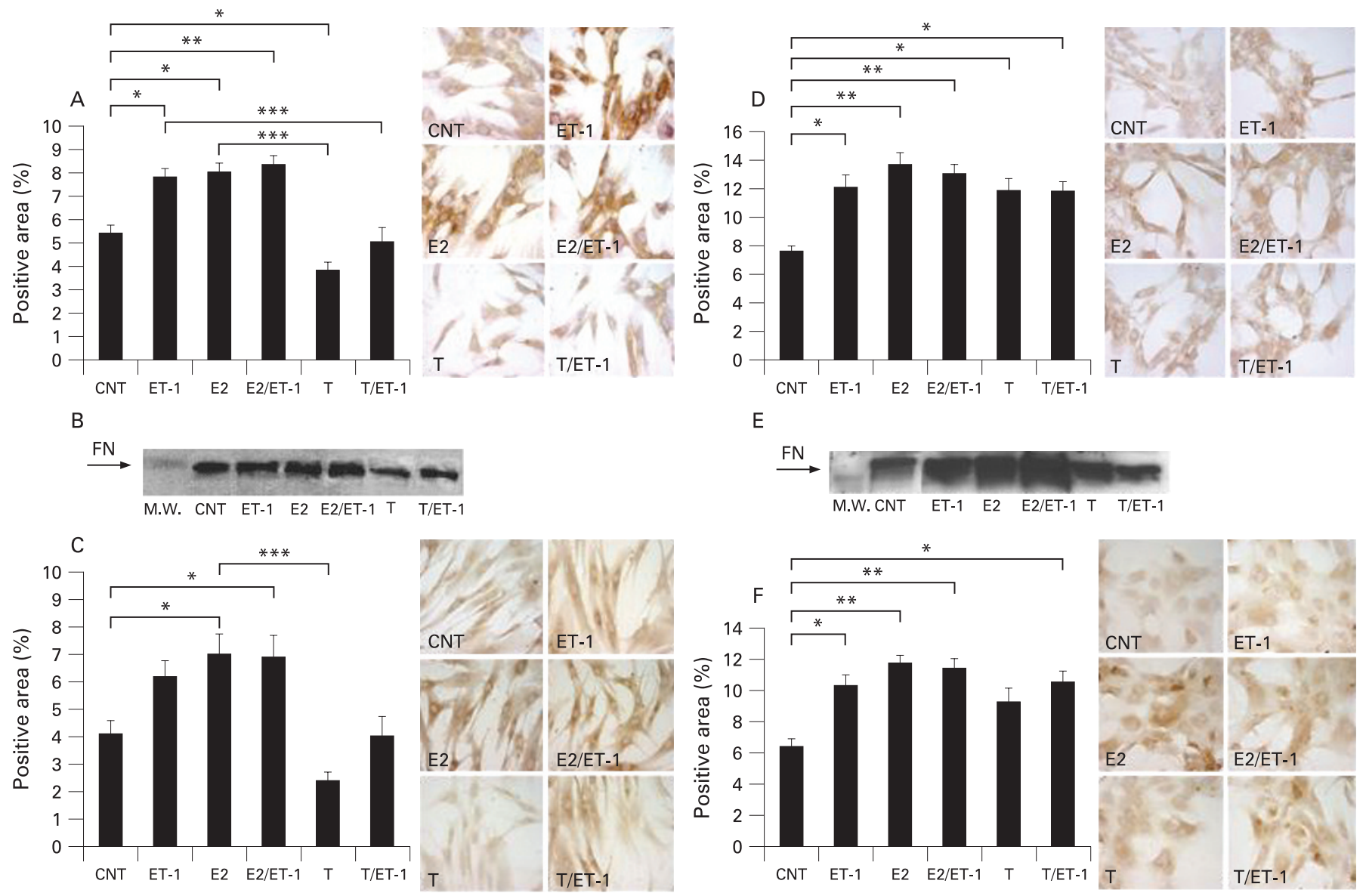

Figure 2 Evaluation by immunocytochemistry $(A)$ and western blot $(B)$ of fibronectin (FN) expression in human normal fibroblasts (Fb) untreated (control) and treated for $24 \mathrm{~h}$ with endothelin-1 (ET-1) $\left(10^{-7} \mathrm{M}\right), 17 \beta$-oestradiol (E2) $\left(10^{-10} \mathrm{M}\right)$, E2 $\left(10^{-10} \mathrm{M}\right)$ with ET-1 (10 $\left.{ }^{-7} \mathrm{M}\right)$, testosterone $(\mathrm{T})$ $\left(10^{-9} \mathrm{M}\right)$ or T $\left(10^{-9} \mathrm{M}\right)$ with ET-1 $\left(10^{-7} \mathrm{M}\right)$. C. Evaluation by immunocytochemistry of laminin expression in human normal Fb untreated (control) and treated for $24 \mathrm{~h}$ with ET-1 $\left(10^{-7} \mathrm{M}\right)$, E2 $\left(10^{-10} \mathrm{M}\right)$, E2 $\left(10^{-10} \mathrm{M}\right)$ with ET-1 $\left(10^{-7} \mathrm{M}\right)$, T $\left(10^{-9} \mathrm{M}\right)$ or T $\left(10^{-9} \mathrm{M}\right)$ with ET-1 (10 $\left.{ }^{-7} \mathrm{M}\right)$. Evaluation by immunocytochemistry (D) and western blot (E) of fibronectin expression in human systemic sclerosis (SSc) Fb untreated (control) and treated for $24 \mathrm{~h}$ with ET-1 $\left(10^{-7} \mathrm{M}\right)$, E2 $\left(10^{-10} \mathrm{M}\right)$, E2 $\left(10^{-10} \mathrm{M}\right)$ with ET-1 $\left(10^{-7} \mathrm{M}\right)$, T $\left(10^{-9} \mathrm{M}\right)$ or T $\left(10^{-9} \mathrm{M}\right)$ with ET-1 (10 $\left.{ }^{-7} \mathrm{M}\right)$. F. Evaluation by immunocytochemistry of laminin expression in human SSc Fb untreated (control) and treated for $24 \mathrm{~h}$ with ET-1 $\left(10^{-7} \mathrm{M}\right), \mathrm{E}^{2}\left(10^{-10} \mathrm{M}\right), \mathrm{E} 2\left(10^{-10} \mathrm{M}\right)$ with ET-1 $\left(10^{-7} \mathrm{M}\right)$, T $\left(10^{-9} \mathrm{M}\right)$ or T $\left(10^{-9} \mathrm{M}\right)$ with ET-1 $\left(10^{-7} \mathrm{M}\right) .{ }^{*} \mathrm{p}<0.05,{ }^{* *} \mathrm{p}<0.01{ }^{* * *} \mathrm{p}<0.001$.

laminin was found (fig 2A,C). E2 alone and in combination with ET-1 induced a further significant increase for fibronectin $(p<0.05, \quad p<0.01$ vs control, respectively) and laminin $(p<0.05, \quad p<0.05$ vs control, respectively) (fig 2A,C). Conversely, $\mathrm{T}$ was found to reduce the expression of both ECM proteins: the decrease was significant for fibronectin $(p<0.05$ vs control) in particular. The fibronectin synthesis was also significantly reduced in FBs cultured in the presence of $\mathrm{T}$ with ET-1 when compared to ET-1-treated cells $(p<0.001)$ (fig 2A). Interestingly, the mean values between E2 and $T$ differed significantly for fibronectin $(p<0.001)$ and laminin $(p<0.001)$ synthesis (fig $2 A, C)$. These data were obtained by immunocytochemistry (ICC).

The ECM protein synthesis was also evaluated by western blot. An evident change vs control was confirmed in particular for the reduced fibronectin expression after $\mathrm{T}$ treatment (fig $2 \mathrm{~B}$ ).

\section{SSc fibroblasts}

ET-1 induced a significant increase of fibronectin and laminin synthesis ( $p<0.05, p<0.05$ vs control, respectively) (fig $2 D, E$ ). Their synthesis was also significantly increased in E2 $(p<0.01$, $\mathrm{p}<0.01$ vs control, respectively) and E2 with ET-1-treated FBs $(\mathrm{p}<0.01, \mathrm{p}<0.01$ vs control, respectively) (fig $2 \mathrm{D}, \mathrm{F})$.
Unexpectedly, $\mathrm{T}$ induced an increase of the ECM protein expression that was significant for fibronectin $(p<0.05$ vs control) (fig 2D). In addition, the treatment with $\mathrm{T}$ and $\mathrm{ET}-1$ was found to induce a significant increase not only for fibronectin ( $p<0.05$ vs control) but also for laminin expression ( $p<0.05$ vs control) (fig 2D,F). These data were observed by ICC and confirmed by western blot, in particular for fibronectin synthesis (fig 2E).

Finally, no statistically significant difference concerning cell proliferation and ECM synthesis by FBs was found between male and female patients with SSc, or in healthy subjects.

\section{DISCUSSION}

The present results indicate that ET-1 is able to increase fibronectin synthesis in normal and SSc human skin FBs, supporting a suggested important role of ET-1 in the pathogenesis of the fibrosis in $\mathrm{SSc}^{2-4}$ as well as in cell proliferation, but limited to normal skin FBs. Interestingly, recent studies have shown that ET-1 induces an increased expression of fibronectin mRNA in cultured peritoneal mesothelial cells and contributes to the ability of TGF- $\beta$ to promote a profibrotic phenotype in human FBs. $^{211}$ The prolonged vasoconstrictor activity and profibrotic effect on FBs by ET-1 might contribute to the pathogenesis of SSc. 
Inflammation and autoimmune reactions are the early events in the fibrotic process that characterise SSc. ${ }^{12}{ }^{13}$ Sex hormones seem to play an important role in the modulation of immune/ inflammatory responses. ${ }^{14}$ Growing evidence indicates that oestrogens and androgens target human skin FBs, influencing the wound repair processes, while elderly men heal wounds more slowly than elderly women and show reduced matrix deposition. ${ }^{12}$ Moreover, E2 has been shown to increase fibroblast proliferation and stimulate synthesis of collagen in women with lower initial collagen levels. ${ }^{8}$ Finally, oestrogen supplementation in postmenopausal women increases skin thickness and collagen content. ${ }^{8}$ Therefore, since SSc is found more frequently in women than men, the present study clearly supports the possible enhancing effect of oestrogens on the SSc fibrotic process.

In particular, E2 increased cell growth, and fibronectin and laminin synthesis in normal and SSc cultured FBs, indicating the involvement of $\mathrm{E} 2$ as a possible enhancer of the fibrotic process. In vivo, this action may be supported by growth factors (ie, connective tissue growth factor (CTGF)) or cytokines, which have been involved in ECM synthesis by SSc FBs. ${ }^{1}$ By contrast, no effect of $\mathrm{T}$ on normal fibroblast growth was observed and $\mathrm{T}$ decreased fibronectin and laminin synthesis. These results seem to support the anti-inflammatory effect of androgens already observed in recent studies. ${ }^{14}$ However, the unexpected enhancement of fibronectin synthesis in T-treated SSc FBs, might well be related to the increased oestrogen synthesis exerted by the enhanced activity of aromatase in activated cells. ${ }^{14}{ }^{15}$ Aromatase metabolises androgens into oestrogens, which increase the intracrine effects on the cells. ${ }^{14}{ }^{15}$ The treatment of normal and SSc FBs was performed with concentrations of sex hormones and ET-1 on the basis of preliminary dose-response curves resulting from testing normal FBs showing optimal cell survival. However, the dose-response curve might be different between SSc and control FBs, and this is a matter for further analysis.

In addition, further studies on SSc FB sex hormone metabolism might better explain the value of these early observations and confirm the possible link between gender and the fibrotic process. Real-time PCR analysis is ongoing, since results from these tests may contribute strongly to confirming these results.

In conclusion, the present study seems to support important synergistic effects for ET-1 and $17 \beta$-oestradiol in the pathogenesis of the fibrotic process in SSc.

Competing interests: None declared.

Ethics approval: Informed consent and ethical committee approval was obtained.

\section{REFERENCES}

1. Abraham DJ, Exckes B, Rajkumar V, Krieg T. New developments in fibroblast and myofibroblasts biology: implications for fibrosis and scleroderma. Curr Rheumatol Rep 2007:9:136-43.

2. Shi-Wen X, Kennedy L, Renzoni EA, Bou-Gharios G, du Bois RM, Black CM, et al. Endothelin is a downstream mediator of profibrotic responses to transforming growth factor $\beta$ in human lung fibroblasts. Arthritis Rheum 2007;56:4189-94.

3. Kawaguchi Y, Suzuki K, Hara M, Hidaka T, Ishizuka T, Kawagoe M, et al. Increased endothelin-1 production in fibroblasts derived from patients with systemic sclerosis. Ann Rheum Dis 1994;53:506-10.

4. Shi-Wen X, Denton CP, Dashwood MR, Holmes AM, Bou-Gharios G, Pearson JD, et al. Fibroblast matrix gene expression and connective tissue remodelling: role of endothelin-1. J Invest Dermatol 2001;116:417-25.

5. Qu LD, Abe M, Yokojama Y, Ishikawa 0 . Effects of $17 \beta$-estradiol on matrix metalloproteinase-1 synthesis by human dermal fibroblasts. Maturitas 2006;54:39-46

6. Kanda N, Watanabe S. 17 $\beta$-estradiol stimulates the growth of human keratinocytes by inducing cyclin D2 expression. J Invest Dermatol 2004;123:319-28.

7. Hall G, Phllips TJ. Estrogen and skin: the effects of estrogen, menopause, and hormone replacement therapy on the skin. J Am Accad Dermatology 2005;53:555-68.

8. Zouboulis CC, Chen WC, Thornton MJ, Qin K, Rosenfield R. Sexual hormones in human skin. Horm Metab Res 2007:39:85-95.

9. Mayes MD, Lacey JV Jr, Beebe-Dimmer J, Gillespie BW, Cooper B, Laing TJ, et al. Prevalence, incidence, survival and disease characteristic of systemic sclerosis in a large US population. Arthritis Rheum 2003;48:2246-55.

10. Cory A.H. Owen TC, Barltrop JA, Cory JG. Use of an aqueous soluble tetrazolium/ formazan assay for cell growth assays culture. Cancer Commun 1991;3:207-12.

11. Shimizu M, Ishibashi Y, Taki F, Shimizu H, Hirahara I, Kaname S, et al. Endothelin(B) receptor blocker inhibits high glucose-induced synthesis of fibronectin in human peritoneal mesothelial cells. Perit Dial Int 2006:26:393-401.

12. Gilliver SC, Wu F, Ashcroft GC. Regulatory roles of androgens in cutaneous wound healing. Thromb Haemost 2003;90:978-85.

13. Abrham DJ, Varga J. Scleroderma: from cell and molecular mechanisms to disease models. Trends Immunol 2005;26:587-95.

14. Cutolo M, Capellino S, Montagna P, Ghiorzo P, Sulli A, Villaggio B. Sex hormone modulation of cell growth and apoptosis of the human monocytic/macrophage cell line. Arthritis Res Ther 2005; 7:R1124-32.

15. Cutolo M, Straub RH, Biilsma JW. Neuroendocrine-immune interactions in synovitis Nat Clin Pract Rheumatol 2007;3:627-34. 